\title{
The evolution of microphysical and optical properties of an A380 contrail in the vortex phase
}

\author{
J.-F. Gayet ${ }^{1}$, V. Shcherbakov ${ }^{1,2}$, C. Voigt ${ }^{3,4}$, U. Schumann ${ }^{3}$, D. Schäuble ${ }^{3}$, P. Jessberger ${ }^{3}$, A. Petzold ${ }^{3}$, A. Minikin ${ }^{3}$, \\ H. Schlager ${ }^{3}$, O. Dubovik ${ }^{5}$, and T. Lapyonok ${ }^{5}$ \\ ${ }^{1}$ LAMP, UMR6016 CNRS/Université Blaise Pascal, Clermont-Ferrand, France \\ ${ }^{2}$ LAMP, Institut Universitaire de Technologie d'Allier, Montluçon, France \\ ${ }^{3}$ Institut für Physik der Atmosphäre, Deutsches Zentrum für Luft- und Raumfahrt (DLR), Oberpfaffenhofen, Germany \\ ${ }^{4}$ Institut für Physik der Atmosphäre, Johannes Gutenberg Universität Mainz, Mainz, Germany \\ ${ }^{5}$ LOA, UMR 8518 CNRS/Université des Sciences et Technologies de Lille, Villeneuve d'Ascq, France
}

Correspondence to: J.-F. Gayet (j.f.gayet@opgc.univ-bpclermont.fr)

Received: 24 June 2011 - Published in Atmos. Chem. Phys. Discuss.: 28 September 2011

Revised: 10 May 2012 - Accepted: 9 July 2012 - Published: 26 July 2012

\begin{abstract}
A contrail from a large-body A380 aircraft at cruise in the humid upper troposphere has been probed with in-situ instruments onboard the DLR research aircraft Falcon. The contrail was sampled during $700 \mathrm{~s}$ measurement time at contrail ages of about 1-4 min. The contrail was in the vortex regime during which the primary wake vortices were sinking $270 \mathrm{~m}$ below the A380 flight level while the secondary wake remained above. Contrail properties were sampled separately in the primary wake at 90 and $115 \mathrm{~s}$ contrail age and nearly continously in the secondary wake at contrail ages from $70 \mathrm{~s}$ to $220 \mathrm{~s}$. The scattering phase functions of the contrail particles were measured with a polar nephelometer. The asymmetry parameter derived from these data is used to distinguish between quasi-spherical and aspherical ice particles. In the primary wake, quasi-spherical ice particles were found with concentrations up to $160 \mathrm{~cm}^{-3}$, mean effective diameter $D_{\text {eff }}$ of $3.7 \mu \mathrm{m}$, maximum extinction of $7.0 \mathrm{~km}^{-1}$, and ice water content (IWC) of $3 \mathrm{mg} \mathrm{m}^{-3}$ at slightly ice-subsaturated conditions. The secondary and primary wakes were separated by an almost particle-free wake vortex gap. The secondary wake contained clearly aspherical contrail ice particles with mean $D_{\text {eff }}$ of $4.8 \mu \mathrm{m}$, mean (maximum) concentration, extinction, and IWC of $80(350) \mathrm{cm}^{-3}$, $1.6(5.0) \mathrm{km}^{-1}$, and $2.5(10) \mathrm{mg} \mathrm{m}^{-3}$, respectively, at conditions apparently above ice-saturation. The asymmetry parameter in the secondary wake decreased with contrail age from 0.87 to 0.80 on average indicating a preferential aspherical ice crystal growth. A retrieval of ice particle habit and
\end{abstract}

size with an inversion code shows that the number fraction of aspherical ice crystals increased from $2 \%$ initially to $56 \%$ at 4 min contrail age. The observed crystal size and habit differences in the primary and secondary wakes of an up to 4 min old contrail are of interest for understanding ice crystal growth in contrails and their climate impact. Aspherical contrail ice particles cause less radiative forcing than spherical ones.

\section{Introduction}

Contrails may have a climate impact similar in magnitude to the radiative forcing from aircraft $\mathrm{CO}_{2}$ emissions (Lee et al., 2009, 2010; Burkhardt and Kärcher, 2011; Schumann et al., 2012). Still the uncertainties of this estimate are large (Heymsfield et al., 2010; Burkhardt et al., 2010; Toohey et al., 2010). In particular, information on ice particle shape is missing (Yang et al., 2010) which may modify the radiative forcing estimate from contrails. The shape of ice crystals determines the forward scattering ratio $(g)$, which in turn has a strong impact on the cloud reflectance and hence on the shortwave radiative forcing (Meerkötter et al., 1999; Yang et al., 2010; Schumann et al., 2012).

Contrails form typically within one wingspan behind the aircraft at temperatures below $-40^{\circ} \mathrm{C}$ when saturation with respect to liquid water is reached in the exhaust plume (Schumann, 1996). After the jet phase, the engine emissions are 
captured within two counter-rotating wake vortices in the downwash behind the aircraft induced by the aircraft lift (Scorer and Davenport, 1970). The primary vortices descend downwards until the rotational vortex motion gets unstable, turbulent and dissipates. The maximum sinking distance depends on ambient stratification, shear, and turbulence and on aircraft properties (Lewellen and Lewellen, 2001; Sussmann and Gierens, 2001; Holzäpfel, 2003; Unterstrasser, 2008; Misaka et al., 2012; Schumann 2012). Ice crystals form early in the jet phase within some tenths of a second. They nucleate in liquid droplets formed by condensation in the liquid-supersaturated exhaust jets on coated and activated soot particles emitted from the aircraft engine or in background aerosol, which is entrained into the exhaust plume (Kärcher and Yu, 2009). Some ice crystals remain near the flight level or are detrained from the descending vortices. They form the secondary wake contrail. A large fraction of the ice crystals remains in the primary wake (Lewellen and Lewellen, 2001; Sussmann and Gierens, 2001). During ice particle formation, humidity inside the contrail drops to ice saturation. Thereafter, ice particles may grow only from humidity entrained from ice-supersaturated ambient air. In subsaturated ambient air, the contrail particles start sublimating. The humidity inside the wake gets further reduced during descent when the air in the sinking primary wake gets compressed and, hence, adiabatically heated (Lewellen and Lewellen, 2001; Unterstrasser and Gierens, 2010). Sussmann and Gierens (1999) simulated the impact of ambient humidity on contrail formation including vortex descent and compared the results to Lidar observations. However, only a few in-situ measurements of contrails in the vortex phase exist (Heymsfield et al., 2010; Schumann et al., 2011a) and none of them differentiates between contrail properties in the primary and in the secondary wake.

Previous studies revealed information on ice particle sizes and concentrations. Ice crystals with effective diameters $D_{\text {eff }}$ below $3.5 \mu \mathrm{m}$ and number concentrations $N_{i}$ above $1000 \mathrm{~cm}^{-3}$ have been detected in contrails younger than $10 \mathrm{~s}$ (Petzold et al., 1997; Heymsfield et al., 1998; Baumgardner and Gandrud, 1998). Voigt et al. (2010) measured ice crystals with $D_{\text {eff }}$ of $5.2 \mu \mathrm{m}$ and $N_{i}$ slightly above $100 \mathrm{~cm}^{-3}$ in the 1-2 min old contrail of a CRJ-2 aircraft. $D_{\text {eff }}$ of $4.8 \mu \mathrm{m}$ and $N_{i}$ near $100 \mathrm{~cm}^{-3}$ were observed in an extensive data set of 14 sub-10 min old contrails from nine different aircraft (Voigt et al., 2011), including some results on the A380 case discussed further below. Poellot et al. (1999) and Schröder et al. (2000) measured contrails in the dispersion regime between $3 \mathrm{~min}$ and $1 \mathrm{~h}$ contrail age. These data were also used for comparison to contrail models (Unterstrasser and Gierens, 2010; Naiman et al., 2011; Schumann, 2012). The measurements and model results show that mean ice particle concentrations decrease and mean ice particle diameters increase in ice supersaturated air masses with contrail age.

Less is known about ice particle shapes. Here, we distinguish between quasi-spherical and aspherical particles.
Quasi-spherical particles have an aspect ratio near one as far as measurable. Ice formation in contrails results from freezing in liquid water droplets which favor a primary quasispherical shape of the fresh ice particles. Quasi-spherical shape of the fresh ice particles have been reported from laboratory studies (Gonda and Takahashi, 1984). From photos of particles collected on a replicator, Schröder et al. (2000) found mainly quasi-spherical ice particles of a few $\mu \mathrm{m}$ sizes. Febvre et al. (2009) measured ice particles in young contrails using a polar nephelometer and size spectrometers similar to the present study and found that the optical properties were controlled mainly by quasi-spherical ice particles with $D_{\text {eff }}$ below $5 \mu \mathrm{m}$, while larger aspherical ice crystals govern the optical properties of 20 min old contrails. Kübbeler et al. (2011) interpret observations of large cirrus ice crystals in spreading contrails to originate mainly from ambient cirrus.

Similarly, extinction measurements in young contrails are scarce. Sussmann and Gierens (1999) report Lidar extinction profiles with peak values of 3 to $70 \mathrm{~km}^{-1}$ in a $20 \mathrm{~s}$ old contrail. Extinctions near $1 \mathrm{~km}^{-1}$ are reported by Voigt et al. $(2010,2011)$ in $1-5$ min old contrails based on calculations from ice crystal size distributions. Febvre et al. (2009) measured extinctions between $0.3-0.5 \mathrm{~km}^{-1}$ in less than 20 min old contrails.

Measuring ice crystal concentration, size, shape and extinction of contrails in the vortex phase is crucial for the initialization and validation of contrail models, since it determines contrail evolution (Lewellen and Lewellen, 2001; Unterstrasser et al., 2008; Unterstrasser and Gierens, 2010; Paugam et al., 2010; Naiman et al., 2011; Schumann, 2012). In addition, improving our understanding on microphysical and optical properties of young contrails may help to reduce the uncertainties in contrail radiative forcing (Yang et al., 2010; Schumann et al., 2011a). The reduction of the climate impact from contrails e.g. via the modification of jet engine emissions (Kärcher and Yu, 2009) or via mitigation studies to avoid contrail formation regions (Mannstein et al., 2005) requires a detailed knowledge on contrail formation and growth. Therefore further measurements of aircraft contrails of different ages were encouraged (Toohey et al., 2010; Heymsfield et al., 2010).

Here, we present in-situ observations of the contrail from a large-body A380 aircraft in the vortex regime. The measurements were performed with instruments onboard the DLR research aircraft Falcon during the CONCERT (CONtrail and Cirrus ExperRimenT) campaign from 22 October to 20 November 2008 above Germany (Voigt et al., 2010). The present analysis used more than $700 \mathrm{~s}$ of observation data in the $70 \mathrm{~s}$ to $220 \mathrm{~s}$ old contrail of an A380 aircraft sampled on 19 November 2008. Microphysical and optical particle properties of the primary and the secondary wakes are presented. We further investigate the evolution of the ice particle shape with contrail age in the secondary wake. An inversion approach is used to interpret the optical contrail properties 
in terms of the fraction of ice particles with non-spherical shape. A closure study between different in-situ instruments is given in Appendix A.

\section{Instrumentation and methods}

During the CONCERT campaign, the DLR Falcon research aircraft was equipped with a set of instruments to measure microphysical particle properties and trace gas composition in the UTLS (Upper Troposphere/Lower Stratosphere) region. Voigt et al. (2010) provide a detailed description of the instruments installed on the aircraft. Below, we briefly introduce the instruments used for our study.

\subsection{Particle probes}

Four particle instruments were used in under-wing stations to detect microphysical and optical properties of contrails and cirrus clouds: (1) the Polar Nephelometer (PN), (2) the Cloud Particle Imager (CPI), (3) the 2D-C, all operated by LaMP, and (4) the FSSP-300 operated by DLR. Thanks to the combination of these independent techniques, particles characterization within a range of diameters varying from typically $0.5 \mu \mathrm{m}$ to $2 \mathrm{~mm}$ was possible. Since this study addresses the properties of a young contrail with ice particle diameters smaller than $20 \mu \mathrm{m}$, only data of the Polar Nephelometer and the FSSP-300 are presented.

The Polar Nephelometer (Gayet et al., 1997) measures the scattering phase function of an ensemble of cloud particles ranging from less than $1 \mu \mathrm{m}$ to about $1 \mathrm{~mm}$ diameter, which intersect a collimated laser beam (wavelength $\lambda=804 \mathrm{~nm}$ ) near the focal point of a parabolic mirror. The sampling volume is defined by the cross sectional area of the beam ( $10 \mathrm{~mm}$ long and $5 \mathrm{~mm}$ diameter) multiplied by the distance travelled during the sample period, i.e. $1 \mathrm{~d} \mathrm{~m}^{-3}$ at a cruise speed of $200 \mathrm{~m} \mathrm{~s}^{-1}$ and a sampling frequency of $10 \mathrm{~Hz}$. Direct measurement of the scattering phase function allows to distinguish particle types (water droplets or ice crystals) and to calculate optical parameters (extinction coefficient Ext and asymmetry parameter $g$, see Gayet et al., 2002). The $g$-value is used as indicator for sphericity; $g$ decreases with increasing asphericity of the particles (Gayet et al., 2002). Nonabsorbing ice particles randomly oriented in the sampling section are assumed in deriving bulk quantities. The accuracies of the extinction coefficient and asymmetry parameter are $25 \%$ and $4 \%$ respectively (Gayet et al., 2002; Jourdan et al., 2010).

For classification of sphericity and for assessment of errors of the asymmetry parameter, we note the sensitivity of the Polar Nephelometer measurements to the particle-shape deviation from a perfect sphere. Mugnai and Wiscombe (1986) used a model of Chebyshev particles to evaluate differences in optical properties between spherical and aspherical particles. They studied different aspherical particles as a function of sphere deformation and waviness. It was shown that for a particle with diameter $D$ of $4 \mu \mathrm{m}$ (size parameter of 15.7 for the PN laser wavelength of $0.8 \mu \mathrm{m}$ ) and for a diameter deviation from spherical of $\Delta D=0.1 D$ the error of the asymmetry parameter estimation is about $4 \%$. This means that within the measurement errors on $g$, a sphere deformation of $10 \%$ cannot be detected by the Polar Nephelometer because the deformation effect is below the sensitivity of the instrument. The corresponding particles hereafter are called "quasi-spherical".

The FSSP-300 (Baumgardner et al., 1992) measures scattering light energy at forward angles which is governed mainly by diffraction and therefore depends on (i) the refractive index of the particles, and (ii) the projected area of the particle which itself depends on the particle shape. The size of an aspherical particle is expressed in terms of equivalent surface diameter, i.e. the diameter of a sphere that has the same projected area (Mishchenko et al., 1997). The method to calibrate the FSSP size for spherical and aspherical particles is presented in Appendix A together with definitions of the microphysical parameters used in this study (extinction coefficient Ext, ice water content IWC, and effective diameter $D_{\text {eff }}$ ). The effective diameter $D_{\text {eff }}$, relevant for extinction and optical depth, is defined as the ratio of volume $V$ to projected cross-section area $A, D_{\text {eff }}=(3 / 2) V / A$, where $V$ and $A$ are computed from the given size distribution. For given ice water content IWC $=\rho_{\text {ice }} V$ and bulk ice density $\rho_{\text {ice }}\left(0.917 \mathrm{~g} \mathrm{~cm}^{-3}\right)$, this diameter is also $D_{\text {eff }}=3 \mathrm{~V} / \mathrm{Ext} \cong 3$ IWC $/\left(\rho_{\text {ice }}\right.$ Ext) (Garret et al., 2003; Schumann et al., 2011a).

According to Field et al. (2003) and Heymsfield (2007), the FSSP-300 and Polar Nephelometer measurements are not likely to be affected by ice crystal-shattering effects since the recorded ice particles are quite small (effective diameter of $4 \mu \mathrm{m}$, maximum particle diameter of $20 \mu \mathrm{m}$ ). The comparison of our contrail data to cirrus observations confirms this hypothesis (Schröder et al., 2000; Voigt et al., 2010).

\section{Trace gas instruments}

Measurements of water vapor inside and outside of ice clouds have been performed with the high precision hygrometer FISH (Fast In situ Stratospheric Hygrometer) operated by FZ Jülich (Zöger et al., 1999; Schiller et al., 2008) and a CR-2 frost point hygrometer operated by DLR (Busen and Buck, 1995; Voigt et al., 2010; Schumann et al., 2011b). Both water vapor instruments use a backward facing inlet to exclude the sampling of ice crystals, thus sample ambient water vapor.

The FISH instrument is based on the Lyman- $\alpha$ photofragment fluorescence technique with a measurement frequency of $1 \mathrm{~Hz}$. The overall uncertainties in the water vapor mixing ratio is $\pm 6 \%$ and in the relative humidity over ice $\left(\mathrm{RH}_{\mathrm{i}}\right)$ $\pm 10 \%$ under the assumption of an uncertainty of $0.5 \mathrm{~K}$ in the temperature measurement (Kübbeler et al., 2011). 
The ambient air temperature was measured on the Falcon with a calibrated PT100 Rosemount sensor and a second uncalibrated one. The individual temperatures detected on that flight differ systematically by about $0.5 \mathrm{~K}$, but the calibration result should be accurate to better than $0.5 \mathrm{~K}$. Still this is a potential source for a systematic underestimation of humidity in the measurements on that day.

The frost point hygrometer CR-2 (Buck Research Instruments) measures the temperature of a mirror carrying a thin frost layer held in equilibrium with the ambient water vapor. The detection limit of the frost point hygrometer is better than $2 \mu \mathrm{mol} \mathrm{mol}{ }^{-1}$ at a pressure of $200 \mathrm{hPa}$ for a time resolution of $2 \mathrm{~s}$. Depending on water vapor gradients, the response time of the frost point hygrometer is in the order of $\sim 1 \mathrm{~s}-1 \mathrm{~min}$. The uncertainty in the water vapor mixing ratio is $\pm 8 \%$ (Schumann et al., 2011b). The uncertainty in $\mathrm{RH}_{\mathrm{i}}$ again depends on the temperature uncertainty and amounts to $\pm 15 \%$, therefore.

$\mathrm{NO}$ and $\mathrm{NO}_{\mathrm{y}}$ mixing ratio measurements were performed using the chemiluminescence technique (Schlager et al., 1997). The technique has extensively been used in previous campaigns for the identification of aircraft exhaust plumes and for the detection of $\mathrm{NO}$ and $\mathrm{NO}_{\mathrm{y}}$ in contrails and cirrus clouds (Schlager et al., 1997; Ziereis et al., 2000; Voigt et al., 2006, 2007; Schäuble et al., 2009). Sample air passes through a backward facing inlet with a fluoropolymer (PFA) tube to sample reactive nitrogen compounds from outside the aircraft. Inside the cabin, the sample air is split into the NO and $\mathrm{NO}_{\mathrm{y}}$ channels of the instrument. In the $\mathrm{NO}_{\mathrm{y}}$ channel, the air first passes through a heated gold converter where the different $\mathrm{NO}_{\mathrm{y}}$ compounds are reduced to $\mathrm{NO}$ using $\mathrm{CO}$ as catalyst. Subsequently the chemiluminescence reaction of NO with $\mathrm{O}_{3}$ is detected. In young tropospheric aircraft plumes $\mathrm{NO}_{\mathrm{y}}$ is mainly composed of $\mathrm{NO}$ and $\mathrm{NO}_{2}$. The accuracy/precision of the NO and $\mathrm{NO}_{\mathrm{y}}$ measurements are $7 / 10 \%$ and $10 / 15 \%$, respectively (Ziereis et al., 2000). The data are recorded with a time resolution of $1 \mathrm{~s}$. Here, we use the $\mathrm{NO}_{\mathrm{y}}$ measurements for the identification of contrails and the differentiation between observations in the primary wake with $\mathrm{NO}_{\mathrm{y}}$ mixing ratios $>30 \mathrm{nmol} \mathrm{mol}^{-1}$ and in the secondary wake.

\section{Detection of the contrail from an A380 passenger aircraft}

Contrail observations were performed on 19 November 2008 on a flight over Germany from Hamburg to Oberpfaffenhofen. The contrail was generated by a commercial A380 aircraft passing Germany at noon on its flight from London to Singapore. It was detected for $16 \mathrm{~min}$ between $12: 14$ to 12:31 universal time (UT) at altitudes of 10420-10700 m, the upper level indicating the flight altitude of the A380 aircraft. The meteorological situation over Germany on that day was influenced by a high pressure system located northwest of France over the Atlantic and a low pressure system over

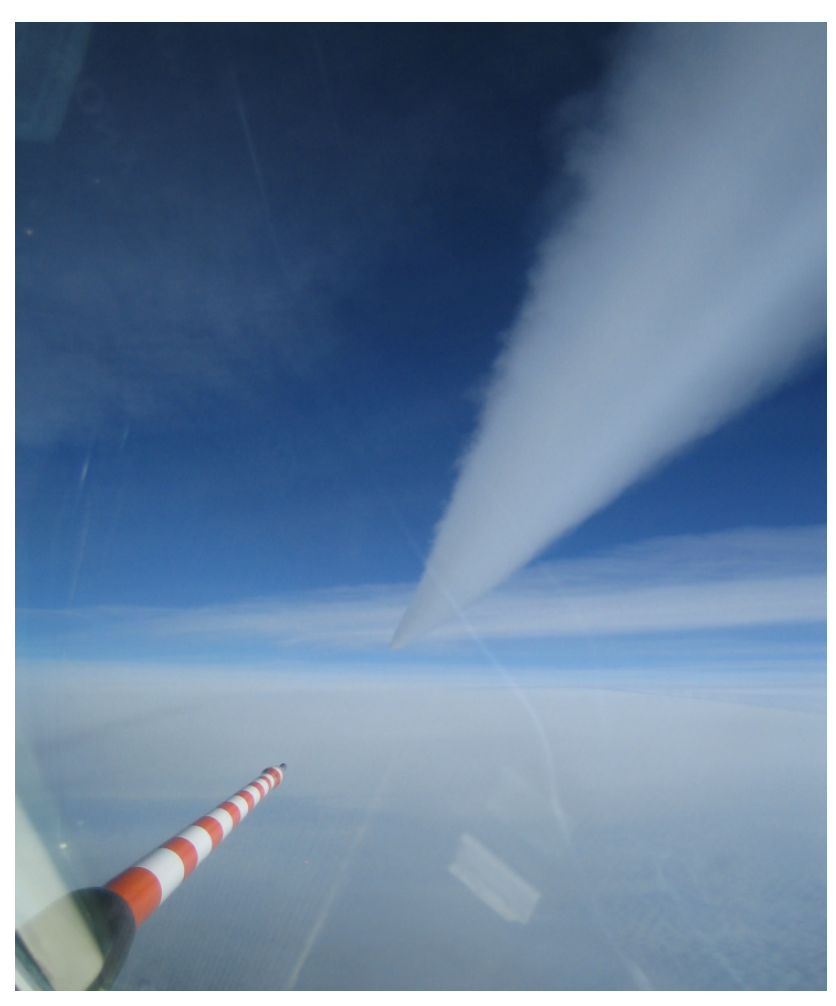

Fig. 1. Photo taken from the Falcon cockpit a few minutes prior the penetration to the A380 contrail (courtesy of T. Jurkat).

northern Scandinavia transporting cold and humid air into the upper troposphere over Germany. At noon that day, a cirrus region moved from the north over Germany. The optically thick A380 contrail was produced above this cirrus region and partly sandwiched in between thin cirrus layers as shown on the photo in Fig. 1 taken a few min before the contrail sampling. At the flight level 350 hectofeet of the A380 $(10700 \mathrm{~m}, 239 \mathrm{hPa})$, the threshold temperature for contrail formation (for estimated ambient $\mathrm{RH}_{\mathrm{i}}$ at ice saturation and for an overall propulsion efficiency of 0.35 ) is $-48.4^{\circ} \mathrm{C}$ $\left( \pm 1.2^{\circ} \mathrm{C}\right)$. The ambient temperature was $-56.5^{\circ} \mathrm{C}$, far below the threshold temperature, so that contrail formation was to be expected according to the Schmidt-Appleman criterion (Schumann, 1996).

The Falcon pilots managed to track the contrail using visual navigation and the guidance of the European air traffic controllers in Maastricht and the German air traffic control (DFS). The real-time indication of several measurements onboard the aircraft (NO/NOy and $\mathrm{CN}$ data, as well as FSSP300 and Polar Nephelometer counts) were used to confirm the contrail penetrations and for guidance to adjust the flight altitude. The Falcon successfully flew inside the contrail for $16 \mathrm{~min}$ at a speed near $200 \mathrm{~m} \mathrm{~s}^{-1}$, slightly lower than the A380 cruise speed, so that the observations were performed at contrail ages from about $70 \mathrm{~s}$ to $270 \mathrm{~s}$ progressively. The contrail was entered from below and penetrated shortly five 


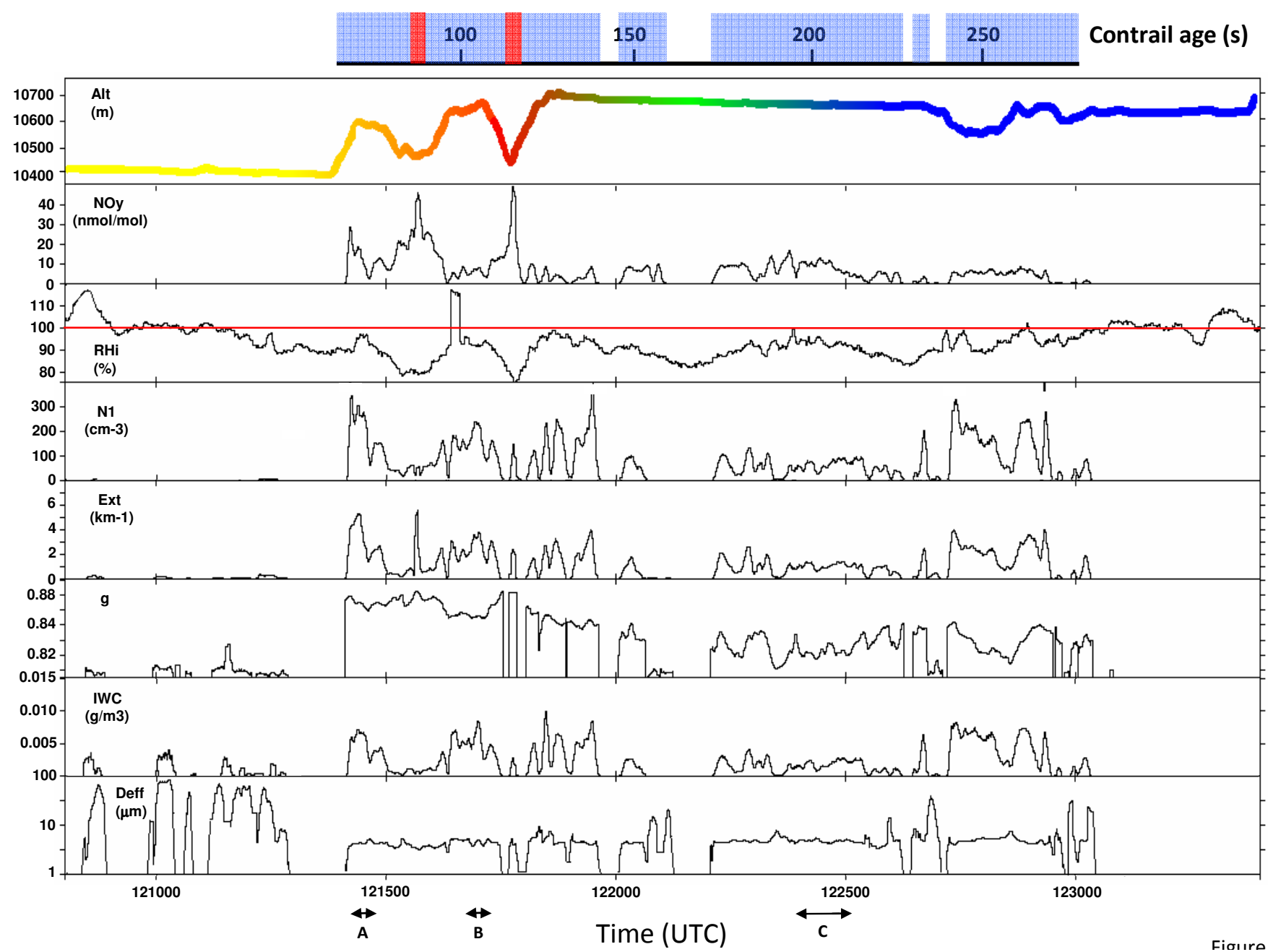

Fig. 2. Time-series at 1-s resolution of measured altitude, $\mathrm{NO}_{\mathrm{y}}$ mixing ratio, relative humidity with respect to ice $\left(\mathrm{RH}_{\mathrm{i}}\right)$, concentrations of particles with diameter greater than $0.9 \mu \mathrm{m}(N 1)$, extinction coefficient (Ext), asymmetry parameter $(g)$, ice water content (IWC), and effective diameter $\left(D_{\text {eff }}\right)$. The top axis shows the separation time between the A380 and Falcon aircraft, indicating the A380 contrail age versus sampling time. The color shading of the altitude time-series reflects this contrail age. The red and blue shaded areas in the top bar represent sampling periods inside the primary and inside the secondary wake of the contrail, respectively. At the lower figure edge, arrows, labeled A, B and C, identify periods selected for retrieval analysis (see Sect. 5).

times initially, followed by an extensive measurement period in the upper contrail part, which turned out to be the secondary wake of the A380. A video movie taken from the cockpit of the Falcon confirms the penetration of the primary wake twice, which was clearly separated from the secondary wake by a vertical wake gap. Later, mainly the secondary wake was probed. The vertical wake gap is typical for twin/four engine aircraft and situations with scattered natural cirrus being present (see scenario 2 on Fig. 2 from Sussmann and Gierens, 1999).

The Falcon performed measurements flying along the contrail, sampling the contrail at different contrail ages. The measurements neither provide a purely Lagrangian (at constant space coordinate versus time) nor Eulerian picture (at constant time versus spatial coordinates). As a conse- quence, changes of contrail properties with age may be partially caused by changes of ambient properties with space along the A380 flight path.

Figure 2 displays time-series of the altitude, the $\mathrm{NO}_{\mathrm{y}}$ mixing ratio and the relative humidity with respect to ice $\left(\mathrm{RH}_{\mathrm{i}}\right)$ along with the microphysical and optical parameters of ice crystals such as the concentration of particles with diameter $>0.9 \mu \mathrm{m}(N 1)$ derived from FSSP-300 data, the extinction coefficient (Ext), and the asymmetry parameter $(g)$ from Polar Nephelometer (PN) data, and the ice water content (IWC) and effective diameter ( $\left.D_{\text {eff }}\right)$ derived from FSSP-300 data. The approximate contrail age at the sampling time is also reported. The contrail age is computed from the observed A380 and Falcon flight tracks taking into account the plume motion for given wind speeds. The altitude time-series is color 

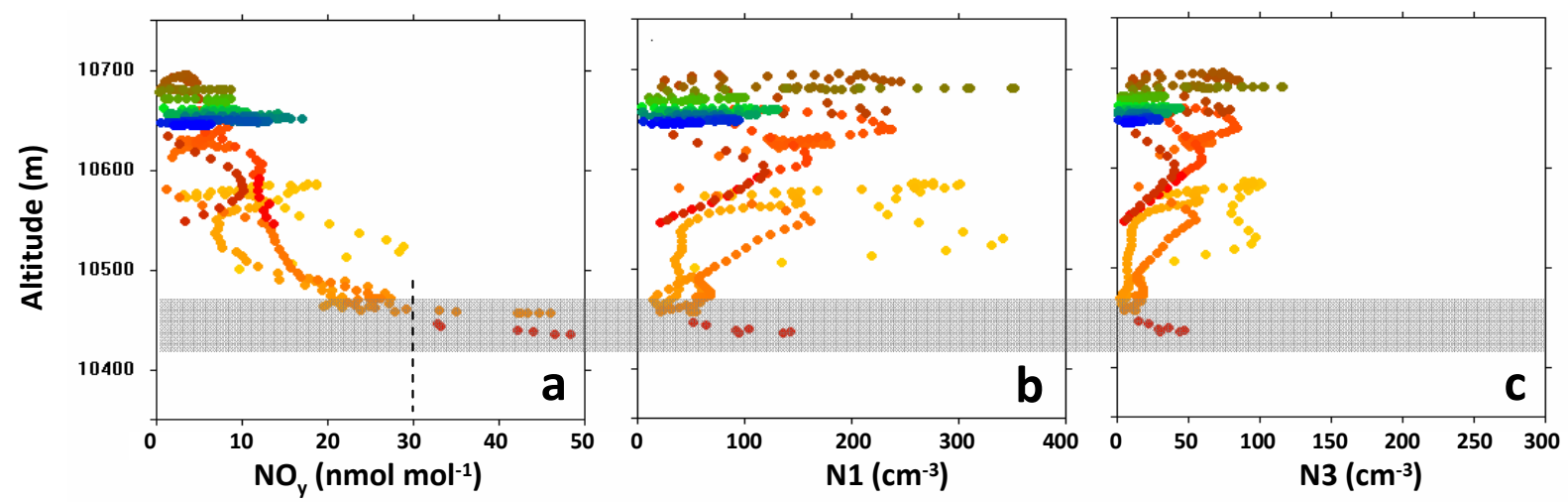

Secondary wake

Primary vortex
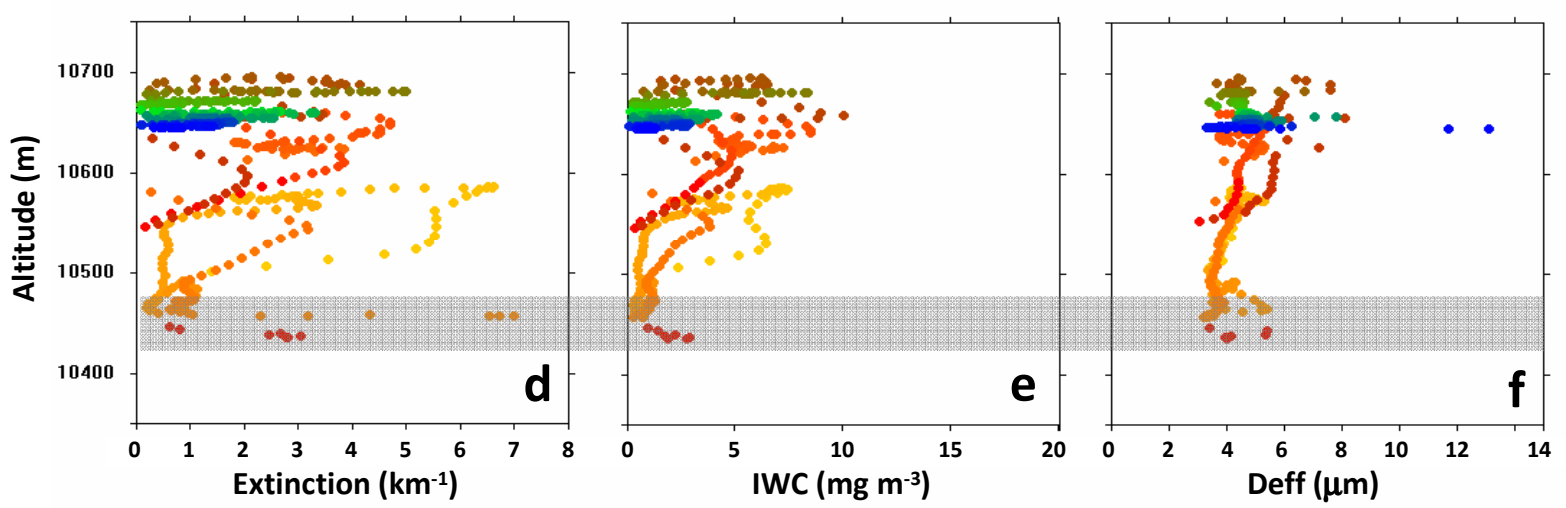

Secondary wake

Primary vortex
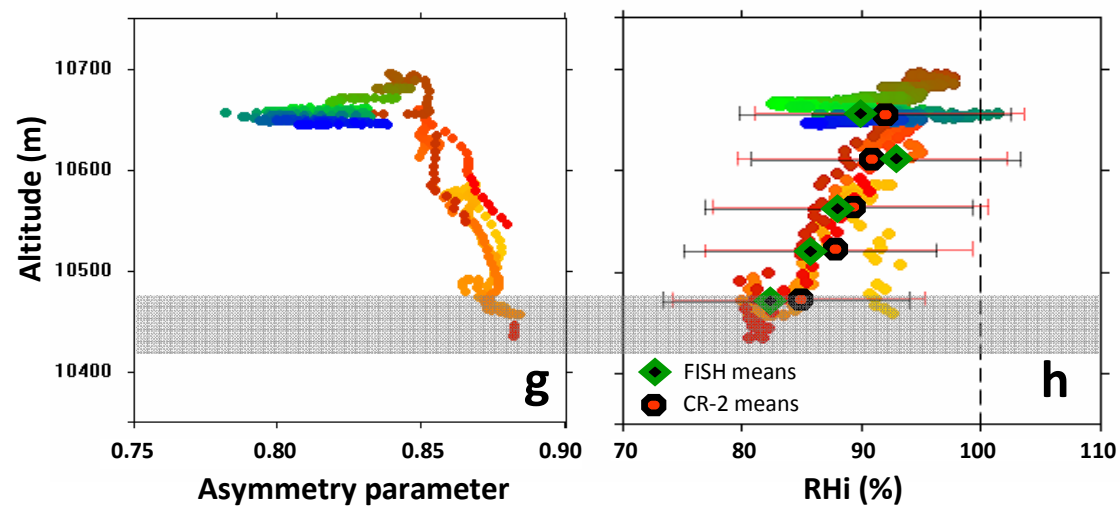

\section{Secondary \\ wake}

\section{Primary}

vortex

Fig. 3. Vertical distribution of parameters (1-s data) measured in the contrail from 12:14:00 UT to 12:26:00 UT (70-220s contrail age, see Fig. 2). (a): $\mathrm{NO}_{\mathrm{y}}$ mixing ratio, (b): concentration of particles $d>0.9 \mu \mathrm{m}$, (c): concentration of particles $d>2.5 \mu \mathrm{m}$, (d): extinction coefficient (PN), (e): ice water content, (f): effective diameter, (g): asymmetry parameter, and (h): relative humidity over ice. Mean FISH and CR-2 values are reported with error bars $( \pm 10$ and $\pm 15 \%$, respectively) which include systematic water vapor mixing ratio and temperature errors. The colors of the symbols indicate contrail ages as shown in Fig. 2.

shaded as a function of contrail age in order to facilitate the discussion of the results represented on the next figure (Fig. 3).

The results show that the Falcon explored the contrail vertical structure five times from $10450 \mathrm{~m} /-54.0^{\circ} \mathrm{C}$ to 10700 $\mathrm{m} /-56.5^{\circ} \mathrm{C}$ and thereafter remained near the $10650 \mathrm{~m}$ level. Generally, the particle data are strongly correlated and FSSP300 and Polar Nephelometer measurements are in a very good agreement on average (see also Fig. A1b in Appendix A).

Small scale heterogeneities of the primary wake on the order of the horizontal distances of the probe mounting positions on the Falcon $(5-10 \mathrm{~m})$ and a low sampling statistics reduce the representativeness of the derived mean contrail parameters in the primary wake, while the secondary wake is well captured by the observations. 


\section{Vertical profile of microphysical and optical contrail properties in the vortex regime}

Figure 3 displays the vertical profiles of several parameters measured between the beginning of the contrail observations (12:14:00 UT, 70 s contrail age) until 12:26:00 UT ( $220 \mathrm{~s}$ contrail age, see Fig. 2). We ignore the contrail observations thereafter, at 220-270 s plume age, occasionally containing large ice crystals mixed in from ambient cirrus clouds, characterized by sharp increases in $D_{\text {eff }}$ (see Fig. 2). As before, the shaded colors of the data points reflect the contrail ages. We observe a general increase in $\mathrm{NO}_{\mathrm{y}}$ mixing ratios with decreasing altitude. The highest $\mathrm{NO}_{\mathrm{y}}$ peak of up to $49 \mathrm{nmol} \mathrm{mol}^{-1}$, indicating lowest dilution, is detected at the lowest sampling levels, in the primary wake. Assuming $\mathrm{NO}_{\mathrm{y}}$ mixing ratios $>30 \mathrm{nmol} \mathrm{mol}^{-1}$ as representative for the primary wake, the primary wake altitudes are found below $10470 \mathrm{~m}$ (shadowed area in Fig. 3). Directly above the primary wake vortex, the wake vortex gap with low concentrations of ice particles is observed. Above the primary counter-rotating vortex pair, buoyancy and detrainment leaves a secondary wake with vertically decreasing particle number concentrations (Gerz et al., 1998; Sussmann, 1999). Smaller mean $\mathrm{NO}_{\mathrm{y}}$ mixing ratios of about $6.4 \mathrm{nmol} \mathrm{mol}^{-1}$ are detected in the upper part of the secondary wake contrail near the flight altitude. Consequently, the secondary wake experiences stronger dilution than the primary wake.

The altitude differences between the top and bottom of the contrail $(\sim 270 \mathrm{~m})$ at a contrail age of $\sim 110 \mathrm{~s}$, implies a descent speed of $2.5 \mathrm{~m} \mathrm{~s}^{-1}$ for the vortex pair. The theoretically expected initial downward vortex speed $(w)$ is (see Holzäpfel and Gerz, 1999):

$w=-\Gamma /(2 \pi b)$

with

$b=s B$

and

$\Gamma=g M /(\rho b U)$

$b$ is the initial vortex spacing, $s$ the spanwise load factor $(s=$ $\pi / 4$ for an elliptic loading), $B$ the wingspan, $\Gamma$ the wake vortex circulation, $\mathrm{M}$ the aircraft mass, $\rho$ the air density and $U$ the true airspeed. For the A380 aircraft $(M=500 \mathrm{Mg}, B=$ $80 \mathrm{~m}$ ) flying at $10500 \mathrm{~m} /-58{ }^{\circ} \mathrm{C}$ (i.e. $\rho=0.383 \mathrm{~kg} \mathrm{~m}^{-3}$ ) at $U=230 \mathrm{~m} \mathrm{~s}^{-1}$ for Mach 0.85 , the expected wake sinking velocity is $w=2.25 \mathrm{~m} \mathrm{~s}^{-1}$. This value agrees well with the observations.

\subsection{Contrail properties in the primary wake}

The primary wake has been observed twice for a dozen of seconds at altitudes below $10470 \mathrm{~m}$ at contrail ages of 90 $\mathrm{s}$ and $115 \mathrm{~s}$ in the vortex regime (see red shaded areas on the time-series in Fig. 2, near 12:15:37 and 12:17:40 UTC), Maximum Ext of $7.0 \mathrm{~km}^{-1}$, IWC of $3 \mathrm{mg} \mathrm{m}^{-3}$ and $N_{i}$ of $140 \mathrm{~cm}^{-3}$ were detected. Due to a low sampling statistics and strong gradients in the observed particle fields, we refrain from giving mean values for these parameters. $D_{\text {eff }}$ in the primary wake ranges between 3-6 $\mu \mathrm{m}$, with mean value of $3.7 \mu \mathrm{m}$. The asymmetry parameter $g$ is maximal in the primary wake, reaching up to 0.87 . This high value suggests that the contrail particles in the primary wake are predominantly spherical or quasi-spherical. This observation is consistent with the vertical humidity gradient within the contrail. The pressure increase associated with the vortex sinking leads to adiabatic heating and subsequent sublimation processes of the ice crystals (Lewellen and Lewellen, 2001). The humidity measurements of the Lyman- $\alpha$ and the frost point measurements displayed on Fig. 3h are near saturation in the secondary wake at the upper level of the contrail and decrease to $84 \%$ in the lower part, the primary wake. Part of the measured humidity profile may originate from vertical humidity variations also outside the contrail. However, in an air parcel at ice saturation at $p=239 \mathrm{hPa}, T=217 \mathrm{~K}$, descending adiabatically by $200 \mathrm{~m}$ without phase change, the humidity would reduce from $100 \%$ to $78 \%$. The observed humidity reduction reduction is slightly smaller possibly because of sublimating ice particles and entrainment of drier ambient air. Hence the ice particles in the primary wake at ages larger $90 \mathrm{~s}$, showing smallest measured sizes and largest asymmetry parameter values, were very likely sublimating. Sublimating ice particles become more spherical with time (Nelson, 1998). Therefore the observations of near-spherical ice particles in the primary wake are reasonable.

\subsection{Contrail properties in the secondary wake}

Quasi continuous observations were performed in the secondary wake at contrail ages 70-220 s (see blue shaded areas in Fig. 2). These observations were interrupted by two crossings of the primary wake (red shaded bars) and two short periods outside the contrail indicated by white areas in the top bar in Fig. 2. Hence, a representative set of data of microphysical properties has been measured in the secondary wake of the A380 at quasi-constant altitude near cruise altitude (10600-10700 m). The mean (maximum) values of $N 1$, Ext and IWC are $80(350) \mathrm{cm}^{-3}, 1.6(5.0) \mathrm{km}^{-1}$ and of 2.5 (10) $\mathrm{mg} \mathrm{m}^{-3}$ respectively. The mean $D_{\text {eff }}$ and $g$ are $4.8 \mu \mathrm{m}$ and 0.82 respectively. In a few cases, the effective diameter approaches $14 \mu \mathrm{m}$. These cases are likely caused by entrainment of larger ice crystals into the contrail, potentially precipitating from the thin scattered cirrus clouds that was observed above the A380 contrail (see Fig. 1). These large ice crystals were detected from both $2 \mathrm{D}-\mathrm{C}$ and CPI instruments.

Figure $3 \mathrm{~g}$ shows the vertical profile of the asymmetry parameter $g$ as derived from the nephelometer measurements. Contrasting with the large scatter of the most other particle properties shown in Fig. 3 (explained by small scale 

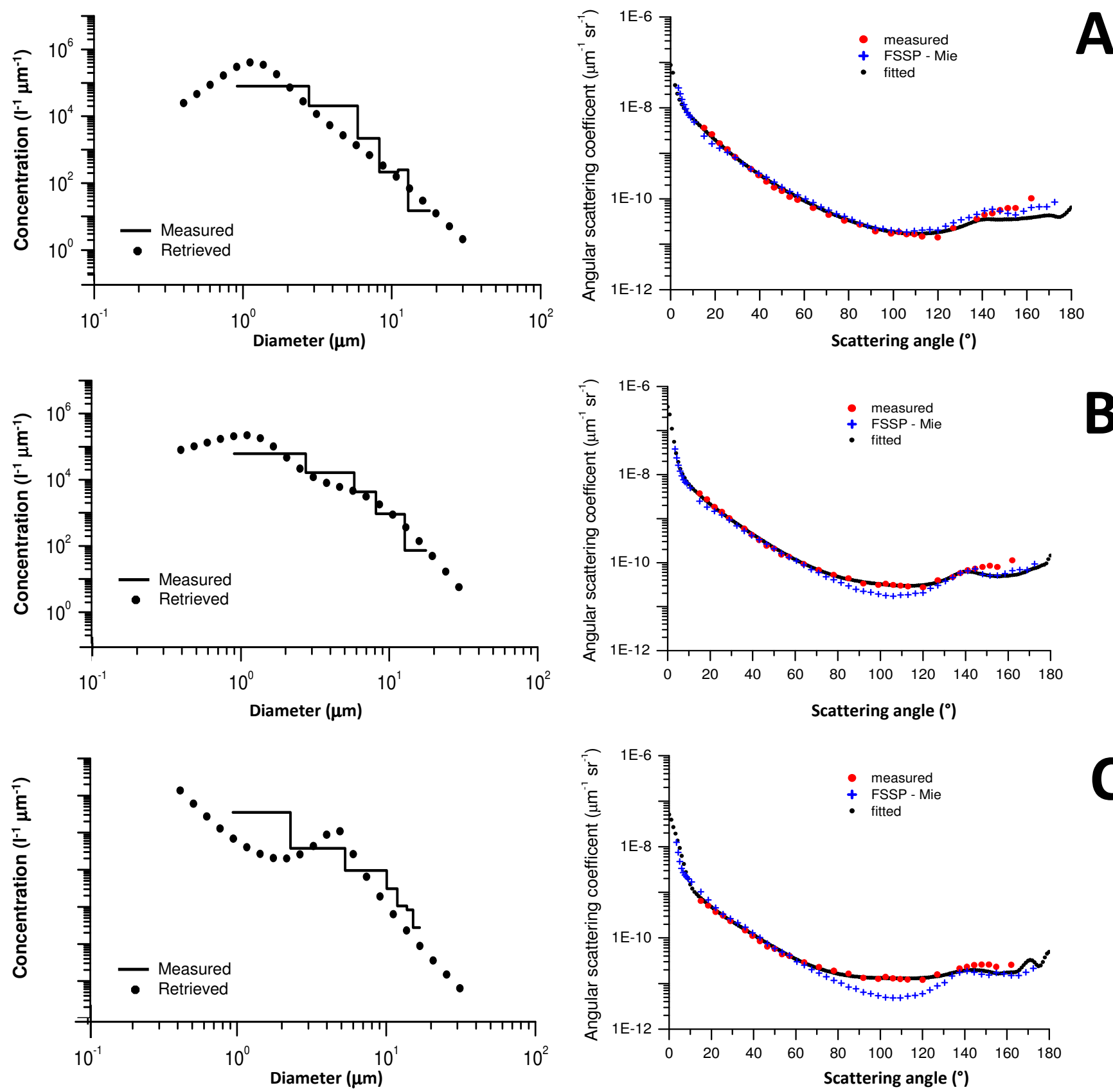

Fig. 4. Left panel: Directly measured particle size distribution (FSSP-300, black lines) and particle size distribution retrieved from the measured scattering phase function (solid black circles). Right panel: Average scattering phase function (solid red circles), theoretical phase function (blue plus-symbols) calculated for spherical ice particles from the FSSP-300 size distribution, and retrieved (solid black circles) scattering phase function. Cases A, B and C refer to the sampling times shown in Fig. 2 at different contrail ages, $50 \mathrm{~s}$, $105 \mathrm{~s}$ and $205 \mathrm{~s}$, respectively.

heterogeneities of the plume), the vertical profile of $g$ shows a rather smooth decrease with the altitude from 0.87 to 0.80 . Based on the measured effective diameters $D_{\text {eff }}>3 \mu \mathrm{m}$ (Fig. 3f), the size parameter $\pi \mathrm{D}_{\text {eff }} / \lambda$ is larger 10 . For this size range, the large $g$-values ( $>0.85$ in our study) are characteristic for spherical or quasi-spherical particles. The smaller the $g$-values, the more aspherical particles are (Gayet et al., 2002; Mishchenko et al., 2002: their Fig. 10.14). The FSSP300 size response dependence on the particle shape is discussed in Appendix A. 

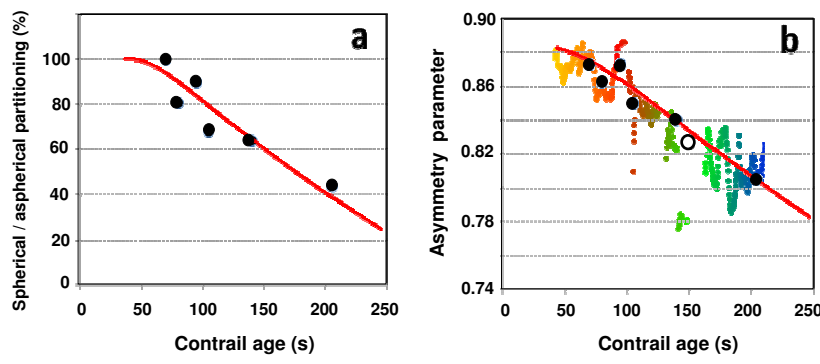

Fig. 5. (a) Spherical/aspherical partitioning ratio (SAR) and (b) asymmetry parameter $g$ versus contrail age. The colored symbols are the measured $g$-values as in Fig. $3 g$. The black dots represent the mean retrieval results (see Sect. 5), and the red lines approximate fits. The single open circle shows the result of Febvre et al. (2009).

\section{Evolution of the partitioning of spherical and aspherical ice particles in the secondary wake of the A380 contrail}

In the secondary wake, the mean asymmetry parameter $g$ decreases with contrail age from about 0.85 to 0.80 , see Fig. 5 b. Hence, these ice particles are progressively loosing spherical shape and become more and more aspherical. The observed increase of the effective diameters from 3.7 to $4.8 \mu \mathrm{m}$ on average (see Fig. 4f) and the formation of aspherical particles during ageing of the secondary wake contrail imply uptake of water from ambient air. The measured amount of ice water content in the contrails cannot be explained with the amount of water emitted by the aircraft engines alone (Schumann, 2012; Voigt et al., 2011). Instead, $\mathrm{RH}_{\mathrm{i}}$ in the secondary wake contrail or in the air entrained into the spreading contrail must have been significantly above $100 \%$ over the contrail life time on average. At the time of contrail observation, the dense contrail might have taken up all previously available supersaturation and just arrived at saturation. The measured $\mathrm{RH}_{\mathrm{i}}$ is systematically below saturation inside the secondarywake contrail. However, a small systematic correction by just $7 \%$ would bring the mean $\mathrm{RH}_{\mathrm{i}}$ from $93 \%$ to $100 \%$. Before and after the measurements inside the contrail, the $\mathrm{RH}_{\mathrm{i}}$ time series (see Fig. 2) also contains some weak hints to supersaturation in ambient air, in particular when increased by $7 \%$. Hence, within the experimental uncertainties of the water vapor and temperature instruments $\left( \pm 10-15 \%\right.$ in $\left.\mathrm{RH}_{\mathrm{i}}\right)$, the observations are consistent with ice saturation inside the contrail and ice supersaturation outside.

In order to determine the fraction of aspherical ice particles and their temporal evolution in the secondary wake contrail, we use the inversion code developed by Dubovik et al. (2006). This code contains kernel look-up tables which allow describing the ensemble of ice particels as an "aerosol" composed of a mixture of spheroids of different aspect ratios and sizes. The code has been used for remote sensing retrievals of atmospheric aerosols. The code offers the possibility to retrieve a complete set of aerosol parameters, includ- ing the complex refractive index and parameters representing size and shape distributions. The software is employed in the operational processing of AERONET (AErosol RObotic NETwork) for retrieving detailed properties from observations of ground-based sun/sky-radiometers (Eck et al., 2008). In this work, the model was applied for the first time to the analysis of ice particle observations in a fresh contrail with diameters below $20 \mu \mathrm{m}$ or size parameters below 80 (for the PN wavelength of $0.8 \mu \mathrm{m}$ ). It should be noted that the original kernels generated by Dubovik et al. (2006) cover the range of the real part of the refractive index from 1.33 to 1.6. For pure water ice, at the laser wavelength of $\lambda=0.8 \mu \mathrm{m}$, we expect a refractive index of about $1.31+i 1.3 \times 10^{-7}$. Therefore, the kernels were extended down to 1.29 for our study.

The contrail clouds are modeled as a mixture of two particle types, one consisting of spherical and one of aspherical particles. Although ice particles are never ellipsoidal, we consider randomly oriented spheroids as a reasonable approximation of small aspherical ice particles. For the distribution of axis ratios of the aspherical fraction, we assume a mixture of oblate and prolate spheroids with the modes at the values of 0.5 and 1.5 , respectively. Furthermore, the partitioning ratio is assumed to be constant over the full size range of the particle size distribution.

Three representative examples of retrievals are discussed below. They were selected to represent the contrail in the secondary wake at ages of $70 \mathrm{~s}, 105 \mathrm{~s}$ and $205 \mathrm{~s}$. The corresponding time-sequences $\mathrm{A}, \mathrm{B}$ and $\mathrm{C}$ are identified in the timeseries in Fig. 2 by horizontal arrows. In Fig. $4 a-c$, the left panel displays the particle size distribution measured with FSSP-300 together with the retrieved one. The size distribution was retrieved along with the refractive index and the spherical/aspherical partitioning ratio (SAR) of ice particles. In the following, the SAR defines the percentage in number of spherical particles relative to the total number of particles. We underscore that the information content of the PN data is inadequate to retrieve a size-dependent partitioning ratio. Variations of the shape and/or the refractive index (from 1.31 to 1.33) of small particles lead to variations of a phase function that are smaller than the PN measurement errors.

Table 1 summarizes the results. For all three cases, the retrieved real part of the refractive index was $1.31 \pm 0.002$. The retrievals indicate that the particles were either nonabsorbing or weakly absorbing with an upper bound for the imaginary part of $10^{-4}$. Variations of the phase functions for the imaginary part within the interval $\left[0 ; 10^{-4}\right]$ are smaller than the measurement errors (Verhaege et al., 2008). For case A, the retrieval results imply that the SAR value was larger than $98 \%$; the SAR estimation error was $\pm 3 \%$ for other cases.

Measured and retrieved averaged scattering phase functions are plotted in Fig. 4 for the three cases, A, B, and C, corresponding to increasing contrail ages. The right panel of Fig. $4 \mathrm{a}-\mathrm{c}$ shows the phase functions (without normalization) measured by the Polar Nephelometer and the FSSP phase function as calculated from the FSSP-300 size distribution 
Table 1. Mean parameter values in the indicated time-intervals and corresponding contrail ages for the three selected contrail regions A, B and $\mathrm{C}$ (see Fig. 2). The parameters are: age, altitude, temperature $T, \mathrm{NO}_{\mathrm{y}}$ mixing ratio, concentration of particles $(d>0.9 \mu \mathrm{m})$, effective diameter $D_{\text {eff }}$, ice water content IWC, direct (PN) and retrieved extinction coefficients (Ext and Ext_ $R$, respectively), asymmetry parameter $g$, spherical/aspherical partitioning ratio (SAR) and residual (Res).

\begin{tabular}{|c|c|c|c|c|c|c|c|c|c|c|c|c|c|}
\hline$\#$ & $\begin{array}{l}\text { UTC time } \\
\text { (h:min:s) }\end{array}$ & $\begin{array}{l}\text { Age } \\
(\mathrm{s})\end{array}$ & $\begin{array}{l}\text { Alt. } \\
(\mathrm{m})\end{array}$ & $\begin{array}{c}T \\
\left({ }^{\circ} \mathrm{C}\right)\end{array}$ & $\begin{array}{c}\mathrm{NO}_{\mathrm{y}} \\
\left(\mathrm{nmol} \mathrm{mol}^{-1}\right)\end{array}$ & $\begin{array}{c}\mathrm{N} 1 \\
\left(\mathrm{~cm}^{-3}\right)\end{array}$ & $\begin{array}{l}D_{\text {eff }} \\
(\mu \mathrm{m})\end{array}$ & $\begin{array}{c}\text { IWC } \\
\left(\mathrm{mg} \mathrm{m}^{-3}\right)\end{array}$ & $\begin{array}{c}\text { Ext } \\
\left(\mathrm{km}^{-1}\right)\end{array}$ & $\begin{array}{c}\text { Ext_R } \\
\left(\mathrm{km}^{-1}\right)\end{array}$ & $g$ & $\begin{array}{l}\text { SAR } \\
(\%)\end{array}$ & $\begin{array}{l}\text { Res. } \\
(\%)\end{array}$ \\
\hline A & $12: 14: 01$ 12:14:21 & 70 & 10536 & -54.5 & 17.1 & 219 & 3.5 & 4.7 & 3.50 & 2.77 & 0.873 & 98 & 13.6 \\
\hline B & 12:16:44 12:17:05 & 105 & 10640 & -55.7 & 6.6 & 193 & 4.4 & 5.9 & 4.29 & 4.08 & 0.850 & 68 & 7.7 \\
\hline $\mathrm{C}$ & $12: 23: 43$ 12:25:04 & 205 & 10651 & -56.8 & 8.5 & 63 & 4.8 & 1.9 & 1.08 & 1.15 & 0.805 & 44 & 9.7 \\
\hline
\end{tabular}

assuming that all ice particles are spherical. The retrieved phase function was computed from the retrieved size distribution and the retrieved SAR. Phase functions were computed for the refractive index $1.31+i 1.0 \times 10^{-4}$. As before, we note that the phase functions are insensitive to changes in the imaginary refractive index below $10^{-4}$.

The main result of Fig. 4 is that the retrieved phase functions agree quite well with the observations from the Polar Nephelometer. This agreement is quantified with the residual values:

Res $=100 \sqrt{\frac{1}{N} \sum_{i=1}^{N}\left[\frac{I_{\text {ret }}\left(\theta_{\mathrm{i}}\right)-I\left(\theta_{\mathrm{i}}\right)_{\text {meas }}}{I\left(\theta_{\mathrm{i}}\right)_{\text {meas }}}\right]^{2}}$,

where $I\left(\theta_{\mathrm{i}}\right)$ is the light intensity at the scattering angle $\theta_{\mathrm{i}}$, and the subscripts "meas" and "ret" refer to the measured and retrieved values, respectively. The residuals are lower than $13.6 \%$, as listed in Table 1 . The remaining residuals are mainly due to uncertainties in the Polar Nephelometer measurements at backward scattering angles $\left(\theta>150^{\circ}\right.$, see Fig. 4). The small residual values show that the employed model fits the measured phase functions quite well. That is, a model using a mixture of spheroids with a size-independent partitioning ratio and the retrieved value of the refractive index gives results which are in good agreement with the observed optical data.

Retrievals were also calculated assuming a model with spherical particles only. In contrast to the mixture of spheroids, the retrieved phase functions for spheres exhibit high residual values for cases $\mathrm{B}$ and $\mathrm{C}$. Hence, these cases can be explained only with aspherical particles.

Compared to the observed size distributions (Fig. 4 left), the retrieved size distributions show roughly the same mode size and spreading for the cases $\mathrm{A}$ and $\mathrm{B}$, but a bimodal feature for case $C$ (Fig. 4c). In all cases, the computed extinction coefficient values match quite well the measured one (see Table 1), highlighting quite robust results with respect to small variations of the observations. We recall that the FSSP-300 probe measures the energy scattered only in the forward direction (between $6^{\circ}$ and $15^{\circ}$ ). Thus, the FSSP-300 data are less sensitive to the particle shape than the PN measurements, which cover a larger interval of scattering angles. It would appear reasonable that the FSSP-300 and the re- trieved size distributions (Fig. 4c, left panel) are interrelated because the theoretical phase function and retrieved scattering phase functions match closely at the forward scattering angles (Fig. 4c, right panel).

Noteworthy results are found by interpreting the optical properties of the three contrail parts. In the secondary wake of the age of $70 \mathrm{~s}$ (Fig. 4a), most ice particles (98\%) are of quasi-spherical shape, as supported by the close agreement between PN measurements and the theoretical FSSP300 phase function. This means that in the younger contrail part, spherical particles control the optical properties of the plume. Figure $4 \mathrm{~b}$, for the $105 \mathrm{~s}$ old contrail, the differences between the measured (PN) and theoretical (FSSP300) phase functions at sideward scattering angles again undoubtedly reveal the occurrence of non-spherical particles. Indeed, the retrieved partitioning ratio of $68 \%$ (see Table 1) indicates that $68 \%$ of the ice particles are spherical and $32 \%$ are aspherical (oblates and prolates). In Fig. 4c, for the 205 s old secondary wake contrail, the differences between the phase functions (PN and FSSP-300) at sideward scattering angles are larger than in the previous case indicating a larger proportion of aspherical ice particles. This feature is confirmed by the retrieved partitioning ratio of $44 \%$. Therefore aspherical particles (assumed as $28 \%$ oblates and $28 \%$ prolates) dominated the optical properties of the secondary wake contrail.

Figure 5 summarizes these results, showing the relationships between the partitioning ratio from the inversion approach (Fig. 5a) and the measured asymmetry parameter (Fig. 5b) versus contrail age (additional inversion results have been drawn on Fig. 5). Extrapolating these results to larger contrail ages, for constant environmental conditions, implies that all ice particles could be aspherically-shaped after 5 min contrail age. The asymmetry parameter may then reach values of 0.77 , which is a typical value for natural cirrus at mid-latitudes (Gayet et al., 2004). The $g$-value reported by Febvre et al. (2009) for a $150 \mathrm{~s}$ old contrail fits well to the present observations (see open circle on Fig. 5b).

It has to be noted that this study is based on $200 \mathrm{~s}$ of measurements in a vortex-phase contrail. This part is a small subset of the 16-min contrail data collected in total behind the A380. Since the shape and size of ice particles depend 
strongly on ambient conditions, the reported results have to be taken as a case study.

\section{Conclusions}

This paper presents for the first time in-situ measurements in the vortex stage of a contrail from a large-body A380 commercial aircraft. The observations cover the contrail vortex regime for contrail ages from $70 \mathrm{~s}$ to $220 \mathrm{~s}$. The measurements cover a large part of the full contrail depth. The measured contrail depth agrees with theoretical predictions. Unique measurements were performed in the primary wake vortex (at 90 and $115 \mathrm{~s}$ contrail age) and in the secondary wake (70-220 s contrail age) at temperatures from $-54.0^{\circ} \mathrm{C}$ to $-56.5^{\circ} \mathrm{C}$.

In the primary wake, spherical or quasi-spherical ice particles with $D_{\text {eff }}$ of $3.7 \mu \mathrm{m}$ and maximum $N_{i}$ of $\sim 160 \mathrm{~cm}^{-3}$ prevail and control the optical properties of the contrail. Maximum values of the extinction coefficient of $7.0 \mathrm{~km}^{-1}$ and the ice water content of $3 \mathrm{mg} \mathrm{m}^{-3}$ were measured. The observed ice subsaturation in the primary wake suggests that ice particles were likely sublimating as confirmed by small particle sizes and a large asymmetry parameter of 0.87 .

In the secondary wake at contrail ages of 70 to $220 \mathrm{~s}$, mean (maximum) values $N_{i}$ of $80(350) \mathrm{cm}^{-3}$, Ext of 1.6 (5.0) $\mathrm{km}^{-1}$, and IWC of 2.5 (10) $\mathrm{mg} \mathrm{m}^{-3}$ were measured. The temporal evolution of the secondary wake contrail could be followed over $150 \mathrm{~s}$ plume age at a quasi-constant level near the A380 cruising altitude. The asymmetry parameter decreased from 0.85 at 1 min plume age to 0.80 on average at $4 \mathrm{~min}$ plume age. This feature illustrates very well the time-evolution of ice crystals towards more aspherical shapes and larger effective diameters ( $4.8 \mu \mathrm{m}$ on average), obviously caused by ice supersaturation during ice crystals growths inside the contrail or in ambient air entrained into the contrail at this level.

A detailed interpretation of the results concerning the shape of the ice particles has been presented. We employed the approach, the code, and the kernels developed by Dubovik et al. (2006). This method offers the possibility to retrieve a consistent set of ice particle parameters fitting the measured scattering phase functions (PN). The retrieved parameters include the size distribution, the refractive index, and the spherical/aspherical ice particle partitioning SAR. This technique, applied to the secondary wake sampled at different ages, gives quite robust results. In the younger contrail (70 s) most of the ice particles $(98 \%)$ have a quasispherical shape. Fractions of aspherical ice particles of $32 \%$ and $56 \%$ are retrieved in the secondary wake at $105 \mathrm{~s}$ and 205 s contrail age, respectively. This means that the number of spherical ice particles decreases with contrail age in accordance with a subsequent decrease of the asymmetry parameter. Extrapolating the results to older contrail ages, suggests that most ice crystals are significantly aspherically-shaped after roughly $5 \mathrm{~min}$ contrail age for constant environmental conditions. This might have implications for the radiative effects from young contrails and contrail cirrus.

\section{Appendix A}

\section{FSSP-300 size calibration and validation with Polar Nephelometer measurements}

The contrail data were first analyzed assuming the FSSP-300 size bin limits related to spherical ice particles. Mie calculations were used to derive: (i) the size bin limits for spherical particles composed of pure ice with a refractive index of $1.31+i 0$, and (ii) the extinction efficiency for the corresponding size bins. The results were adjusted to the calibrated probe response of the specific FSSP-300 used during CONCERT. In order to minimize the Mie ambiguities related to the probe size response, 22 channels (10-31) were rebinned to 8 channels giving a diameter range from $0.9 \mu \mathrm{m}$ to $22.9 \mu \mathrm{m}$ in this case. For dense contrail encounters, FSSP300 channels no. 30 and 31 were found to be overcounting, while this was not the case for less dense cirrus encounters. Coincidence effects may explain this effect (Baumgardner et al., 1992) and therefore these channels were excluded from the data analysis.

The extinction coefficient (Ext) is calculated from the FSSP-300 size distribution with the ice water content (IWC) and the effective diameter ( $\left.D_{\text {eff }}\right)$ with the following equations:

$$
\begin{aligned}
& \mathrm{Ext}=\pi / 4 \sum_{i=1}^{i=8} \beta_{\mathrm{ext}}^{i} N_{i} D_{i}^{2} \\
& \mathrm{IWC}=\pi / 6 \cdot \rho_{\mathrm{ice}} \sum_{i=1}^{i=8} N_{i} D_{i}^{3} \\
& D_{\text {eff }}=3271 \cdot \mathrm{IWC} / \mathrm{Ext}
\end{aligned}
$$

with $\beta_{\text {ext }}^{i}$ the extinction efficiency, $D_{i}$ the mean diameter in channel $i, N_{i}$ the number concentration and $\rho_{\text {ice }}$ the ice bulk density $\left(0.917 \mathrm{~g} \mathrm{~cm}^{-3}\right)$. Equation (3) is based on the relation between projected cross sectional area of particles and extinction for constant extinction efficiency and particle ice bulk density $\rho_{\text {ice }}$ (Garrett et al., 2003). $D_{\text {eff }}$ is expressed in $\mu \mathrm{m}$, IWC in $\mathrm{g} \mathrm{m}^{-3}$ and Ext in $\mathrm{km}^{-1}$.

Figure A1a displays the comparison between the extinction coefficients derived from the FSSP-300 and the Polar Nephelometer. As shown in Sect. 4.2 the asymmetry parameter $(g)$, gives an indication on the particle shape (see also Febvre et al., 2009), with quasi-spherical particles expected for $g$ larger than 0.85 and aspherical ice crystals for smaller values. The red and blue square symbols on Fig. A1a were sorted out according to the $g$-values, i.e. $g>0.85$ and $g<0.85$, respectively. The results clearly show a rather good agreement between the two extinction measurements 

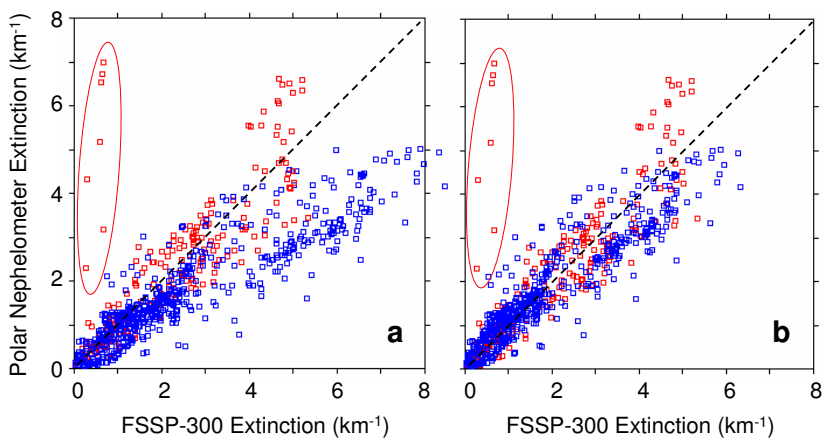

Fig. A1. Comparison of extinction coefficients derived from FSSP300 and from Polar Nephelometer (PN) measurements. FSSP-300 with different size calibrations: (a) for spherical particles, (b) for spherical (red data) and aspherical (blue data) depending on the value of the PN-derived asymmetry parameter $g$. The red and blue square symbols refer to asymmetry parameter values $g>0.85$ and $g<0.85$, respectively.

for quasi-spherical ice particles (red data). As for the aspherical particles (blue data) the extinction from the FSSP300 is significantly overestimated with respect to the Polar Nephelometer data. This result is a strong indication that the FSSP-300 size calibration is dependent on the particle shape and that the assumption of spherical particles for the FSSP size calibration is not valid for data points with $g<0.85$.

Size bins for non-spherical particles were defined from T-matrix calculations by Borrmann et al. (2000) assuming aspherical (i.e. rotationally symmetric ellipsoid) particles (composed of pure ice) with an aspect ratio of 1:2. The size calibration is expressed in terms of equivalent surface diameter, i.e. the diameter of a sphere that has the same projected area (Mishchenko et al., 1997). In this case, nine channels describe the diameter range from $0.9 \mu \mathrm{m}$ to $19.5 \mu \mathrm{m}$. For data characterized by $g$ smaller than 0.85 (aspherical particles), the microphysical parameters are derived with the equations above by considering $D_{i}$ the equivalent surface diameter. The subsequent extinction coefficients are compared to the Polar Nephelometer measurements on Fig. A1b with blue square symbols $(g<0.85)$. The results show a much better agreement than before between the two measurements whatever the particle shape. This closure method validates the proposed FSSP-300 size calibrations.

The $g$-threshold of 0.85 to separate spherical and aspherical particle shapes is warranted by the best fit and the smaller dispersion of the scattered data on Fig. A1b (the slope parameter of the linear fit and correlation coefficient are 0.93 and 0.92, respectively). Of course, these results could be refined by considering a smooth FSSP size-bin transition between the two considered particle-shape calibrations. It should be noticed that particles with diameters below $0.9 \mu \mathrm{m}$ can be neglected since they contribute little to the extinction coefficient, showing that the contrail optical properties are controlled by larger particles.
In Fig. A1a and b, some data (red symbols) reveal a large overestimation of the PN measurements. These data correspond to primary wake vortex observations during which the PN sampled the plume whereas the FSSP-300 (mounted on the opposite wing) was likely out of the contrail due to smallscale heterogeneities of the vortex properties.

Acknowledgements. The CONCERT campaign was organized by the HGF-young investigators group AEROTROP under the grant VH-NG-309. Part of this work was funded within the DLR-project CATS (Climate-compatible Air Transport System) and by the DFG SPP HALO 1294 (grant number VO-1504/2-1). This work was funded by a grant from the CNRS/INSU. We thank the DLR flight department for extraordinary flights. We thank M. Kübbeler and M. Krämer for providing FISH humidity measurements and detailed discussions leading to improvements of the analysis, and T. Hamburger for FSSP-300 instrument preparation. K. Gierens is thanked for helpful discussions. We thank C. Gourbeyre and J.-F. Fournol (LaMP) for their technical assistance. The Deutsche Lufthansa (A. Waibel) and the European and German air traffic control (DFS) are gratefully acknowledged for their excellent support of the campaign. The authors are grateful to D. Baumgardner and the anonymous reviewer for important comments that strengthened the manuscript.

Edited by: P. Spichtinger

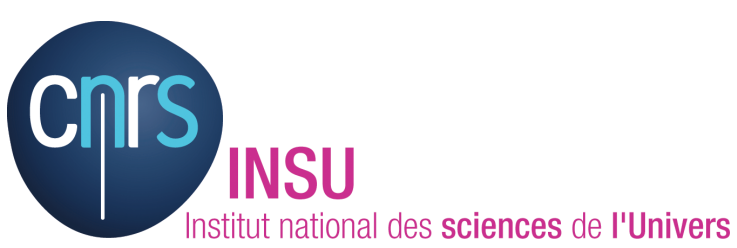

The publication of this article is financed by CNRS-INSU.

\section{References}

Baumgardner, D. and B. W. Gandrud: A comparison of the microphysical and optical properties of particles in an aircraft contrail and mountain wave cloud, Geophys. Res. Lett., 25(8), 11291132, doi:10.1029/98GL00035, 1998.

Baumgardner, D., Dye, J. E., Gandrup, B. W., and Knollenberg, R. G.: Interpretation of measurements made by the Forward Scattering Spectrometer Probe (FSSP-300) during the Airborne Arctic Stratosphere Expedition, J. Geophys. Res., 97, 8035-8046, 1992.

Borrmann, S., Luo, B., and Mishchenko, M.: Application of the T-matrix method to the measurement of aspherical (ellipsoidal) particles with forward scattering optical particle counters, J. Aerosol Sci., 31, 789-799, 2000.

Burkhardt, U. and Kärcher, B.: Global radiative forcing from contrail cirrus, Nature Clim. Change 1, 54-58, doi:10.1038/nclimate1068, 2011.

Burkhardt, U., Kärcher, B., and Schumann, U.: Global modelling of the contrail and contrail cirrus climate impact, B. Am. Meteorol. Soc., 91, 479-484, doi:10.1175/2009BAMS2656.1, 2010. 
Busen, R. and Buck, A. L.: A high-performance hygrometer for aircraft use: Description, installation, and flight data, J. Atmos. Ocean. Technol., 12, 73-84, doi:10.1175/1520-0426, 1995.

Dubovik, O., Sinyuk, A., Lapyonok, T., Holben, B. N., Mishchenko, M., Yang, P., Eck, T. F., Volten, H., Muñoz, O., Veihelmann, B., van der Zande, W. J., Leon, J.-F., Sorokin, M., and Slutsker, I.: Application of spheroid models to account for aerosol particle nonsphericity in remote sensing of desert dust, J. Geophys. Res., 111, D11208, doi:10.1029/2005JD006619, 2006.

Eck, T. F., Holben, B. N., Reid, J. S., Sinyuk, A., Dubovik, O., Smirnov, A., Giles, D., O’Neill, N. T., Tsay, S.-C., Ji, Q., Al Mandoos, A., Ramzan Khan, M., Reid, E. A., Schafer, J. S., Sorokine, M., Newcomb, W., and Slutsker, I.: Spatial and temporal variability of column-integrated aerosol optical properties in the southern Arabian Gulf and United Arab Emirates in summer, J. Geophys. Res., 113, D01204, doi:10.1029/2007JD008944, 2008.

Febvre, G., Gayet, J.-F., Minikin, A., Schlager, H., Shcherbakov, V., Jourdan, O., Busen, R., Fiebig, M., Kärcher, B., and Schumann, U.: On optical and microphysical characteristics of contrails and cirrus, J. Geophys. Res., 114, D02204, doi:10.1029/2008JD010184, 2009.

Field, P. R., Wood, R., Brown, P. R. A., Kaye, P. H., Hirst, E., Greenaway, R., and Smith, J. A.: Ice particle interarrival times measured with a fast FSSP, J. Atmos. Ocean. Technol., 20, 249-261, 2003.

Garrett, T. J., Gerber, H., Baumgardner, D. G., Twohy, C. H., and Weinstock, E. M.: Small, highly reflective ice crystals in low-latitude cirrus, Geophys. Res. Lett., 30, 2132, doi:10.1029/2003GL018153, 2003.

Gayet, J. F., Crépel, O., Fournol, J. F., and Oshchepkov, S.: A new airborne polar Nephelometer for the measurements of optical and microphysical cloud properties. Part I: Theoretical design, Ann. Geophys., 15, 451-459, doi:10.1007/s00585-997-0451-1, 1997.

Gayet, J.-F., Asano, S., Yamazaki, A., Uchiyama, A., Sinyuk, A., Jourdan, O., and Auriol, F.: Two case studies of winter continental-type water and mixed-phase stratocumuli over the sea: 1. Microphysical and optical properties, J. Geophys. Res., 107, 4569, doi:10.1029/2001JD001106, 2002.

Gayet, J.-F., Ovarlez, J., Shcherbakov, V., Ström, J., Schumann, U., Minikin, A., Auriol, F., Petzold, A., and Monier, M.: Cirrus cloud microphysical and optical properties at southern and northern midlatitudes during the INCA experiment, J. Geophys. Res., 109, D20206, doi:10.1029/2004JD004803, 2004.

Gerz, T., Dürbeck, T., and Konopka, P.: Transport and effective diffusion of aircraft emissions, J. Geophys. Res., 103, 2590525913, doi:10.1029/98JD02282, 1998.

Gonda R. and Takahashi, T.: Initial growth forms of snow crystals growing from frozen droplets, J. Meteor. Soc. Jpn., 62, 190-192, 1984.

Heymsfield, A., Baumgardner, D., DeMott, P., Forster, P., Gierens, K., and Kärcher, B.: Contrail microphysics, B. Am. Meteor. Soc., 91, 465-472, doi:10.1175/2009BAMS2839.1, 2010.

Heymsfield, A. J.: On measurements of small ice particles in clouds, Geophys. Res. Lett., 34, L23812, doi:10.1029/2007GL030951, 2007.

Heymsfield, A. J., Lawson, P. R., and Sachse, G. W.: Growth of ice crystals in a precipitating contrail, Geophys. Res. Lett., 25, 1335-1338, 1998.
Holzäpfel, F.: Probabilistic two-phase wake vortex decay and transport model, J. Aircraft, 40, 323-331, 2003.

Holzäpfel, F. and Gerz, T.: Two-dimensional wake vortex physics in the stably stratified atmosphere, Aerosp. Sci. Technol., 5, 261270, 1999.

Jourdan, O., Mioche, G., Garret, T. J., Schwarzenbock, A., Vidot, J., Xie, Y., Shcherbakov, V., Duroure, C., Yang, P., and Gayet, J.-F.: Coupling of the microphysical and optical properties of arctic clouds during the ASTAR 2004 experiment: Implications for light scattering modelling, J. Geophys. Res., 115, D23206, doi:10.1029/2010JD014016, 2010.

Jurkat, T., Voigt, C., Arnold, F., Schlager, H., Kleffmann, J., Aufmhoff, H., Schäuble, D., Schäfer, M., and Schumann, U.: Measurements of $\mathrm{HONO}, \mathrm{NO}, \mathrm{NO}_{\mathrm{y}}$ and $\mathrm{SO}_{2}$ in aircraft exhaust plumes at cruise, Geophys. Res. Lett., 38, L10807, doi:10.1029/2011GL046884, 2011.

Kärcher, B. and Yu, F.: The role of aircraft soot emissions in contrail formation, Geophys. Res. Lett., 36, L01804, doi:10.1029/2008GL036649, 2009.

Kübbeler, M., Hildebrandt, M., Meyer, J., Schiller, C., Hamburger, T., Jurkat, T., Minikin, A., Petzold, A., Rautenhaus, M., Schlager, H., Schumann, U., C. Voigt, Spichtinger, P., Gayet, J. F., Gourbeyre, C., and Krämer, M.: Thin and subvisible cirrus and contrails in a subsaturated environment, Atmos. Chem. Phys., 11, 5853-5865, doi:10.5194/acp-11-5853-2011, 2011.

Lee, D. S., Fahey, D. W., Forster, P. M., Newton, P. J., Wit, R. C. N., Lim, L. L., Owen, B., and Sausen, R.: Aviation and global climate change in the 21st century, Atmos. Environ., 43, 35203537, doi:10.1016/j.atmosenv.2009.04.024, 2009.

Lee, D. S., Pitari, G., Grewe, V., Gierens, K., Penner, J. E., Petzold, A., Prather, M. J., Schumann, U., Bais, A., Berntsen, T., Iachetti, D., Lim, L. L., and Sausen, R.: Transport impacts on atmosphere and climate: Aviation, Atmospheric Environment, Atmos. Environ., 44, 4678-4734, doi:10.1016/j.atmosenv.2009.06.005, 2010.

Lewellen, D. C. and Lewellen, W. S.: The effects of aircraft wake dynamics on contrail development, J. Atmos. Sci., 58, 390-406, 2001.

Mannstein, H., Spichtinger, P., and Gierens, K.: A note on how to avoid contrail cirrus, Transp. Res., 421-426, 2005.

Meerkötter, R., Schumann, U., Minnis, P., Doelling, D. R., Nakajima, T., and Tsushima, Y.: Radiative forcing by contrails, Ann. Geophys., 17, 1080-1094, doi:10.1007/s00585-999-10807, 1999.

Misaka, T., Holzäpfel, F., Hennemann, I., Gerz, T., Manhart, M., and Schwertfirm, F.: Vortex bursting and tracer transport of a counter-rotating vortex pair, Phys. Fluids, 24, 025104, doi:10.1063/1.3684990, 2012.

Mishchenko, M. I., Travis, L. D., Kahn, R. A., and West, R. A.: Modeling phase functions for dustlike tropospheric aerosols using a mixture of randomly oriented polydisperse spheroids. J. Geophys. Res., 102, 16831-16847, doi:10.1029/96JD02110, 1997.

Mishchenko, M. I., Travis, L. D., and Lacis, A. A.: Scattering, Absorption, and Emission of Light by Small Particles, Cambridge University Press, Cambridge, UK, 2002.

Mugnai, A. and Wiscombe, W. R.: Scattering from nonspherical Chebyshev particles. I: Cross-sections, single-scattering albedo, asymmetry factor and backscatterd fration, Appl. Optics, 25, $1235-1244,1986$. 
Naiman, A. D., Lele, S. K., and Jacobson, M. Z.: Large eddy simulations of contrail development: Sensitivity to initial and ambient conditions over first twenty minutes, J. Geophys. Res., 116, D21208, doi:10.1029/2011JD015806, 2011.

Nelson, N.: Sublimation of Ice Crystals, J. Atmos. Sci., 55, 910 919, 1998.

Paugam, R., Paoli, R., and Cariolle, D.: Influence of vortex dynamics and atmospheric turbulence on the early evolution of a contrail, Atmos. Chem. Phys., 10, 3933-3952, doi:10.5194/acp-103933-2010, 2010.

Petzold, A., Busen, R., Schröder, F. P., Baumann, R., Kuhn, M., Ström, J., Hagen, D., Whitefield, P., Baumgardner, D., Arnold, F., Borrmann, S., and Schumann, U.: Near field measurements on contrail properties from fuels with different sulfur content, J. Geophys. Res., 103, 29867-29880, 1997.

Poellot, M., Arnott, W., and Hallett, J.: In situ observations of contrail microphysics and implications for their radiative impact, J. Geophys. Res., 104, 12077-12084, doi:10.1029/1999JD900109, 1999.

Schäuble, D., Voigt, C., Kärcher, B., Stock, P., Schlager, H., Krämer, M., Schiller, C., Bauer, R., Spelten, N., de Reus, M., Szakáll, M., Borrmann, S., Weers, U., and Peter, Th.: Airborne measurements of the nitric acid partitioning in persistent contrails, Atmos. Chem. Phys., 9, 8189-8197, doi:10.5194/acp-9-8189-2009, 2009.

Schiller, C., Krämer, M., Afchine, A., Spelten, N., and Sitnikov, N.: The ice water content in Arctic, midlatitude and tropical cirrus, J. Geophys. Res., 113, D24208, doi:10.1029/2008JD010342, 2008.

Schlager, H., Konopka, P., Schulte, P., Schumann, U., Ziereis, H., Arnold, F., Klemm, M., Hagen, D. E., Whitefield, P. D., and Ovarlez, J.: In situ observations of air traffic emission signatures in the North Atlantic flight corridor, J. Geophys. Res., 102, 10739-10750, doi:10.1029/96JD03748, 1997.

Schröder, F., Kärcher, B., Duroure, C., Ström, J., Petzold, A., Gayet, J. F., Strauss, B., Wendling, P., and Borrmann, S.: On the transition of contrails into cirrus clouds, J. Atmos. Sci., 57, 464-480, 2000.

Schumann, U.: On conditions for contrail formation from aircraft exhausts, Meteorol. Z., 5, 4-23, 1996.

Schumann, U.: A contrail cirrus prediction model, Geosci. Model Dev., 5, 543-580, doi:10.5194/gmd-5-543-2012, 2012.

Schumann, U., Mayer, B., Gierens, K., Unterstrasser, S., Jessberger, P., Petzold, A., Voigt, C., and Gayet, J.-F.: Effective radius of ice particles in cirrus and contrails, J. Atmos. Sci., 68, 300-321, doi:10.1175/2010JAS3562.1, 2011a.

Schumann, U., Weinzierl, B., Reitebuch, O., Schlager, H., Minikin, A., Forster, C., Baumann, R., Sailer, T., Graf, K., Mannstein, H., Voigt, C., Rahm, S., Simmet, R., Scheibe, M., Lichtenstern, M., Stock, P., Rüba, H., Schäuble, D., Tafferner, A., Rautenhaus, M., Gerz, T., Ziereis, H., Krautstrunk, M., Mallaun, C., Gayet, J.F., Lieke, K., Kandler, K., Ebert, M., Weinbruch, S., Stohl, A., Gasteiger, J., Groß, S., Freudenthaler, V., Wiegner, M., Ansmann, A., Tesche, M., Olafsson, H., and Sturm, K.: Airborne observations of the Eyjafjalla volcano ash cloud over Europe during air space closure in April and May 2010, Atmos. Chem. Phys., 11, 2245-2279, doi:10.5194/acp-11-2245-2011, 2011 b.

Schumann, U., Mayer, B., Graf, K., and Mannstein, H.: A parametric radiative forcing model for contrail cirrus, J. Appl. Meteorol. Clim., 51, doi:10.1175/JAMC-D-11-0242.1, 2012.
Scorer, R. S. and Davenport, L. J.: Contrails and aircraft downwash, J. Fluid Mech., 43, 451-464, 1970.

Sussmann, R.: Vertical dispersion of an aircraft wake: Aerosol-lidar analysis of entrainment and detrainment in the vortex regime, J. Geophys. Res., 104, 2117-2129, 1999.

Sussmann, R. and Gierens, K.: Lidar and numerical studies on the different evolution of vortex pair and secondary wake in young contrails, J. Geophys. Res., 104, 2131-2142, 1999.

Sussmann, R. and Gierens, K.: Differences in early contrail evolution of 2-engined versus 4-engined aircraft. Lidar measurements and numerical simulations, J. Geophys. Res., 106, 4899-4912, 2001.

Toohey, D., McConnell, J., Avallone, L., and Evans, W.: Aviation and Chemistry and Transport Processes in the Upper Troposphere and Lower Stratosphere, B. Am. Meteor. Soc., 91, 485490, doi:10.1175/2009BAMS2841.1, 2010.

Unterstrasser, S., Gierens, K., and Spichtinger, P.: The evolution of conrail microphysics in the vortex phase, Meteorol. Z., 17, 145156, 2008.

Unterstrasser, S. and Gierens, K.: Numerical simulations of contrail-to-cirrus transition - Part 1: An extensive parametric study, Atmos. Chem. Phys., 10, 2017-2036, doi:10.5194/acp-102017-2010, 2010.

Verhaege, C., Shcherbakov, V., and Personne, P.: Limitations on retrieval of complex refractive index of spherical particles from scattering measurements, JQSRT, 109, 2338-2348, 2008.

Voigt C., Schlager, H., Ziereis, H., Kärcher, B., Luo, B. P., Schiller, C., Krämer, M., Popp, P. J., Irie, H., and Kondo, Y.: Nitric acid in cirrus clouds, Geophys. Res. Lett., 33, L05803, doi:10.1029/2005GL025159, 2006.

Voigt, C., Kärcher, B., Schlager, H., Schiller, C., Krämer, M., de Reus, M., Vössing, H., Borrmann, S., and Mitev, V.: In-situ observations and modeling of small nitric acid-containing ice crystals, Atmos. Chem. Phys., 7, 3373-3383, doi:10.5194/acp7-3373-2007, 2007.

Voigt, C., Schumann, U., Jurkat, T., Schäuble, D., Schlager, H., Petzold, A., Gayet, J.-F., Krämer, M., Schneider, J., Borrmann, S., Schmale, J., Jessberger, P., Hamburger, T., Lichtenstern, M., Scheibe, M., Gourbeyre, C., Meyer, J., Kübbeler, M., Frey, W., Kalesse, H., Butler, T., Lawrence, M. G., Holzäpfel, F., Arnold, F., Wendisch, M., Döpelheuer, A., Gottschaldt, K., Baumann, R., Zöger, M., Sölch, I., Rautenhaus, M., and Dörnbrack, A.: In-situ observations of young contrails - overview and selected results from the CONCERT campaign, Atmos. Chem. Phys., 10, 90399056, doi:10.5194/acp-10-9039-2010, 2010.

Voigt, C., Schumann, U., Jessberger, P., Jurkat, T., Petzold, A., Gayet, J.-F., Krämer, M., Thornberry, T., and Fahey, D.: Extinction and optical depth of contrails, Geophys. Res. Lett., 38, L11806, doi:10.1029/2011GL047189, 2011.

Yang, P., Hong, G., Dessler, A. E., Ou, S. S. C., Liou, K.-N., Minnis, P., and Harshvardhan: Contrails and Induced Cirrus: Optics and Radiation, B. Am. Meteor. Soc., 91, 473-478, doi:10.1175/2009BAMS2837.1, 2010.

Ziereis, H., H. Schlager, P. Schulte, P. F. J. van Velthoven, and F. Slemr: Distributions of $\mathrm{NO}, \mathrm{NO}_{\mathrm{x}}$, and $\mathrm{NO}_{\mathrm{y}}$ in the upper troposphere and lower stratosphere between $28_{-}$and $61 \_\mathrm{N}$ during POLINAT 2, J. Geophys. Res., 105, 3653-3664, doi:10.1029/1999JD900870, 2000. 
Zöger, M., Afchine, A., Eicke, N., Gerhards, M.-T., Klein, E., McKenna, D., Mörschel, U., Schmidt, U., Tan, V., Tuitjer, F., Woyke, T., and Schiller, C.: Fast in situ stratospheric hygrometers: A new family of balloon-borne and airborne Lymanphotofragment fluorescence hygrometers., J. Geophys. Res., 104, 1807-1816, 1999. 